9 CEREBRAL SINUS VENOUS THROMBOSIS, PRESEPTAL CELLULITIS, AND MENINGITIS IN THE SETTING OF FUSOBACTERIUM ACUTE MASTOIDITIS: A CASE REPORT

Ivana Valenčak-Ignjatić*, Diana Didović, Ante Šokota, Lorna Stemberger Marić, Srðan Roglić, Goran Tešović. University Hospital for Infectious Diseases „Dr. Fran Mihaljević, Zagreb, Croatia

\subsection{6/archdischild-2021-europaediatrics.9}

Background Acute mastoiditis (AM) is a frequent complication of acute otitis media in children. Osteomyelitis of the temporal bone, extra and intracranial abscesses, meningitis or sinus venous thrombosis (SVT) are common complications of AM. Over the last decade, a change in the etiology of AM in pediatric patients has occured. Rates of bacteria such as Streptococcus pneumoniae, Haemophilus influenzae, and Moraxella catharralis are declining, while other pathogens, manly Group A Streptococcus and Fusobacterium necrophorum are increasing.

Case Report Summary A 4-year old boy was admitted at University Hospital for Infectious Diseases 'Dr. Fran Mihaljević', Zagreb, during October 2019 on the 4th day of fever, vomiting, respiratory symptoms and earache. On physical examination, his vital signs were normal, he had redness and edema of the right eye without internal and external ophthalmoplegia. Otoscopy revealed purulent otorrhea in the right external auditory canal. Neck stiffness was present without a focal neurological deficit. Laboratory tests revealed elevated inflammatory parameters with a white blood cell (WBC) count of $27 \times 109 / \mathrm{L}$ and C-reactive protein of $213,4 \mathrm{mg} / \mathrm{L}$. Lumbar puncture revealed pleocytosis of 7087 white cells $/ \mu \mathrm{L}$ (neutrophils $85,3 \%)$, moderately elevated protein level $(0,86 \mathrm{~g} / \mathrm{L})$ and glucose concentration of $1,9 \mathrm{mmol} / \mathrm{L}$.

Empiric intravenous antibiotic therapy with ceftriaxone was started at the admission. Despite treatment, the patient was febrile with the onset of headache and somnolence. The patient underwent contrast-enhanced computer tomography (CT) which revealed signs of complete opacification of mastoid air cells with diffuse soft-tissue thickening and areas of enhancement anterior to the orbital septum along with the increase in attenuation of the right cavernous sinus. Cranial Magnetic Resonance Imaging (MRI) showed contrast filling deficit in the right cavernous sinus due to sinus thrombosis. Microbiological analysis of the cerebrospinal fluid and purulent exudate releaved Fusobacterium spp. Blood culture remained sterile.

Antibiotic therapy was changed to metronidazole with the addition of low molecular weight heparin. Metronidazole therapy was maintained for 24 days, and anticoagulant therapy with warfarin was continued after the hospital discharge. The patient recovered completely without neurological sequelae.

Discussion A growing incidence of Fusobacterium spp AM and its high rate of complications suggest the need for greater awareness of this pathogen. Based on recent studies, most authors recommend the use of metronidazole in combination with third generation cephalosporin in the treatment of AM in children.

\section{0 \\ RELATIONSHIP BETWEEN GESTATIONAL WEIGHT GAIN AND NEONATAL OUTCOME INDICATORS IN UNDERWEIGHT WOMEN IN CROATIA}

Ivan Cerovečki*, Željka Draušnik, Urelija Rodin. Croatian Institute of Public Health

10.1136/archdischild-2021-europaediatrics.10

To investigate the association between gestational weight gain in underweight women (BMI $<18.5 \mathrm{~kg} / \mathrm{m} 2$ ) with occurrence of preterm delivery and 5-minute Apgar scores lower than 7 in neonates. Preterm birth, maternal underweight and high gestational weight gain have all been linked with adverse neonatal outcomes, such as neonatal death or long-term disability.

However, some previous studies have suggested that high gestational weight gain in underweight women, unlike in other women, may not act as conducive to preterm birth. Moreover, higher-than-average gestational weight gain rates in underweight women have been hypothesised to have a positive effect on physical growth and intellectual development of early school-aged children.

An observational study was undertaken, analysing all records on live-born children collected in years 2016, 2017 and 2018 in the National Birth Record Database of the Croatian Institute of Public Health. All records with lacking or erroneous data on maternal weight (pregravid and at birth), height, gestational age at birth or 5-minute Apgar scores were excluded.

Thereafter, all records on women with a pregravid BMI equal to or greater than $18.5 \mathrm{~kg} / \mathrm{m} 2$ were eliminated from the study. The remaining birth records $(\mathrm{N}=4613)$ were analysed using a linear regression model in order to determine the association between gestational weight gain (expressed as the BMI unit increment throughout the entire duration of pregnancy) and gestational age at birth (records categorised in two-week intervals in the $22-43$ week range), as well as 5minute Apgar scores.

Gestational weight gain had an observed value range of $0.31-13.96 \mathrm{~kg} / \mathrm{m} 2$ in the studied population. It was found to have a negative association with gestational age at birth in neonates $(\mathrm{p}<0.001)$ and a positive correlation with 5 -minute Apgar-scores $(\mathrm{p}<0.005)$. However, gestational weight gain accounted only for a small proportion of variance in both gestational age at birth and 5-minute Apgar score values (multiple R2 values: 0.27 and 0.16 , respectively).

Greater gestational weight gain values in underweight women are associated with a higher probability of full term delivery and higher 5-minute Apgar scores, both serving as important predictors of neonatal outcome. However, such outcomes are affected by various other factors influencing maternal health and obstetric care, warranting further research in this field in order to ameliorate neonatal health care provision. 